Chapter 10

\title{
New Systemic Treatment Approaches for Metastatic Renal Cell Carcinoma
}

\author{
Thean Hsiang Tan, Sina Vatandoust and \\ Michail Charakidis
}

Additional information is available at the end of the chapter

http://dx.doi.org/10.5772/55280

\section{Introduction}

Kidney cancer comprises 2-3\% of all cancers according to Cancer Research UK statistics. (http:// info.cancerresearchuk.org). Renal Cell Carcinomas (RCC) is the most common subtype (around 90\%) with clear-cell variant constituting up to $75 \%$ of all RCCs. Non clear-cell variant are less common and consist of papillary (Type I and II; 10-15\%), chromophobe (4\%) and collecting duct (including the rare medullary variant; $<1 \%$ ). [1, 2] At initial diagnosis, one third of patients have evidence of distant metastases, and amongst patients who undergo curative nephrectomy, a third will have a recurrence within 5 years. Historically, treatment options have been limited in metastatic RCC, as cytotoxic chemotherapy is not effective in this disease and immunotherapy is of modest benefit. [1] The treatment outlook for metastatic RCC has changed in the past decade, with the introduction of new therapeutic agents which target molecular pathways involved in tumour angiogenesis.

\section{Molecular pathogenesis}

\subsection{Clear- cell variants renal cell carcinoma}

The discovery of von Hippel-Lindau (VHL) / hypoxia-inducible factor (HIF) oxygen-sensing pathway and its role in the pathogenesis of RCC (clear-cell as well as some of the non-clearcell variant), has led to a new approach in the systemic therapy for RCC. [1, 3] Tumour suppressor gene VHL encodes the VHL protein ( $\mathrm{pVHL}$ ), which interacts with hypoxiainducible factor (HIF) to regulate cellular response to oxygen deprivation. HIF is a gene 
transcription factor and consists of two subunits: HIF $\alpha$-subunit and the HIF $\beta$-subunit (also known as aryl hydrocarbon receptor nuclear translocator (ARNT) protein). In the presence of normal oxygen tension (or normoxic state), HIF- $\alpha$ is hydroxylated. pVHL-E3 ubiquitin ligase complex targets the hydroxylated HIF- $\alpha$ for proteosomal degradation. [4] VHL protein functions as the substrate-recognition subunit of this complex. [5, 6]

VHL gene mutation or hypermethylation leads to intracellular accumulation of HIF- $\alpha$ subunits. [7] HIF- $\alpha$ subunits, after translocation into thenucleus, actin concert with theHIF- $\beta$ subunits, and form transcriptional factor complexes that induce transcription of hypoxia-response genes. [8] The endpoint is an increase in the production of pro-angiogenic factors including vascular endothelial growth factor (VEGF), platelet-derived growth factor (PDGF) and transforming growth factor alpha and beta (TGF- $\alpha$ and TGF- $\beta$ ). [9] By increasing angiogenesis through VHLHIF pathway the tumour increases its potential to survive and progress. [10]

\subsection{Non clear-cell variant}

Papillary carcinomas are commonly bilateral, multifocal and frequently present as small, early stage tumours. [11] They can be further subdivided histologically into papillary types I and II with underlying different genetics and molecular pathways. [12] Type I papillary renal cancers are linked to activating mutations of the methyl-nitroso-nitroguanidine induced (MET) oncogene. [13] The MET oncogene mutations activate the intracellular kinase domains and subsequently trigger the hepatocyte growth / MET pathway. [13] Type II papillary renal cancers on the other hand are associated with mutations of the fumarate hydratase $(\mathrm{FH})$ tumour suppressor gene. [14] Mutational inactivation of the FH tumour suppressor gene leads to a pseudo-hypoxic state and up-regulation of the HIF $\alpha$-subunits. The accumulation of fumarate is induced by the mutated FH enzyme. That in turn causes inhibition of HIF-prolyl hydroxylase $(\mathrm{HPH})$, an enzymatic regulator of the intracellular HIF- $\alpha$. Inactivation of the HPH disrupts the hydroxylation of HIF leading to failure of recognition by pVHL and subsequent VHL-dependent proteosomal degradation of HIFs. Accumulation of HIF leads to overexpression of pro-angiogenic factors and tumour proliferation. [15]

Chromophobe renal cell cancers accounts for $4 \%$ of all RCCs. [1] The exact pathogenesis is not established. It is thought that the VEGF-angiogenic pathway is implicated based on the elevated levels of VEGF and its receptors in this type of RCC. The KIT oncogene and the folliculin gene linked to the familial form of chromophobe/oncocytic RCC hybrid (Brit-HoggDubé-Syndrome), are extra molecular targets identified in this variant [16, 17] Collecting duct RCC are very rare and the underlying pathogenesis has not been established. [18]

\section{Systemic treatment of metastatic renal cell carcinoma}

The current guidelines from the National Comprehensive Cancer Network Metastatic (NCCN) continue to identify nephrectomy as an important initial consideration, even in the context of metastatic disease. [19] The current recommendations are to consider patients for nephrectomy and/or oligmetastatectomy prior to initiation of systemic therapy whenever appropriate. [20] 
The traditional teaching is that cytoreductive nephrectomy lead to improved outcome from systemic therapy. This is based on phase III data that showed an improvement in response to IFN- $\alpha$ following nephrectomy in the metastatic setting. In the era of targeted therapy / antiVEGF therapies, the validity of this practice has been called into question. [20] Clinical trials are underway to address this very question.

Beyond surgery, the only systemic options available prior to the era of targeted therapy consisted of interleukin-2 (IL-2) and interferon- $\alpha$ (IFN- $\alpha$ ). Other treatments that had been trialed included chemo- and hormonal therapy have all been discouraging. [21]

IFN- $\alpha$ classically caused flu-like syndrome, depression and in some cases suicidal ideation and is certainly onerous especially in the patients with poorer performance status. [1, 22] IL-2, the other cytokine has a small long term survival benefit of $4 \%$. This is however at the cost of potentially life threatening toxicities such as hypotension, oliguria, capillary leak syndrome with secondary multi-organ failure, somnolence and confusion. [23] Not surprisingly, the underlying enthusiasm for cytokine agents as frontline therapy in metastatic RCC has been replaced by tyrosine kinase inhibitors / targeted therapy which has a more favourable toxicity profile. [24]

The targeted therapies used in metastatic RCC consist of 1 . Anti-VEGFs, which are monoclonal antibodies that bind directly to VEGF and related peptides and therefore removing them from the circulation (bevacizumab) and 2. Small molecule tyrosine kinase inhibitors (SMTKIs) that target the down-stream tyrosine kinase signaling pathways, are involved in promotion of tumour angiogenesis, endothelial growth, proliferation and ultimately tumour survival and metastasis. [25] The SMTKIs that have been approved for use in 2012 include sunitinib, sorafenib, pazopanib and axitinib.

\subsection{Small molecular tyrosine kinase inhibitors}

\subsubsection{Sunitinib}

Sunitinib is a multi-kinase inhibitor targeting numerous VEGF receptors (VEGF-1, 2, 3) and additional tyrosine kinase receptors (PDGFR, c-Kit, FLT-3, CSF-1R, and RET) [26-29] Early trials showed sunitinib to be effective in patients with advanced malignancies including RCC. [30]

\subsubsection{Sunitinib intermittent dosing}

A phase II study of sunitinib in patients with cytokine-refractory metastatic RCC assessed the clinical efficacy and safety of sunitinib as second-line therapy. [31] Sixty three patients who previously failed cytokine-based therapy received 50mg of sunitinib for 4 weeks followed by a 2 week scheduled break, in a 6 week cycle. A partial response of $40 \%(n=25)(P R)$ and a stable disease response for $\geq 3$ months in $27 \%(n=17)$ of the patients were reported. The median time to progression and survival were 8.7 months and 16.4 months respectively. [31]

A second but larger phase II trial of 106 patients similarly confirmed promising activities of sunitinib in cytokine refractory, metastatic RCC. An overall objective response of $44 \%$ was observed with $1 \%(n=1)$ of patients demonstrated a CR and $44 \%$ showed PR. [32] A further 
$22 \%(n=23)$ of patients showed SD for $\geq 3$ months. The median response for the 46 responders was 10 months whilst the median progression free survival (PFS) was 8.3 months [32]

These results led to a phase III trial comparing sunitinib with INF- $\alpha$ that was deemed standard of care at the time for patients with metastatic clear cell RCC. [33] Seven hundred and fifty treatment naïve patients with clear-cell histology and good performance status (ECOG 0 or 1 ) were randomized in a 1:1 ratio to receive either sunitinib (dose as per earlier studies) or INF$\alpha\left(9 \times 10^{6}\right.$ units subcutaneously thrice weekly). $[32,34]$ The median duration of treatment was 6 months (1-15 months) in the sunitinib group and 4 months (1-13 months) in the IFN- $\alpha$ group. The median PFS assessed by an independent third-party review was 11 months in the sunitinib group and 5 months in the IFN- $\alpha$ group, corresponding to a hazard ratio (HR) of $0.42(95 \% \mathrm{CI}$ 0.32-0.54; $\mathrm{p}<0.001)$. [33] The investigators' assessment showed similar results. An updated analysis published in 2009 has shown the ORR of $47 \%$ for sunitinib and $12 \%$ for IFN- $\alpha$ ( $\mathrm{p}<$ $0.000001)$, with a median PFS of 11 months and 5 months, respectively, for sunitinib and IFN$\alpha(p<0.000001)$, similar to the original report. [35] These results were uniformly seen, regardless of the patients' age, gender and prognostic category. Patients on sunitinib also experienced a median OS in excess of 2 years. The OS was 26.4 months for sunitinib and 21.8 months for IFN- $\alpha(\mathrm{p}=0.051)$. [33] However, a dedicated exploratory analysis of patients on both treatment arms who did not receive post-study cancer treatment showed the median OS with sunitinib was twice as long as IFN- $\alpha$ (28.1 months versus 14.1 months respectively, $p=0.003)$. [33] Based on these significant findings, sunitinib replaced IFN- $\alpha$ as first line treatment for stage IV RCC.

In a real-world setting, sunitinib has proven its efficacy in an expanded-access program, designed to allocate access to sunitinib in patients with metastatic RCC who would otherwise be excluded from clinical trials. [33,36] Four thousand five hundred patients were enrolled in this international, open labeled study. The cohort importantly included older patients $(\geq 65$ years old; $n=1414)$, those with poorer ECOG status ( $\geq 2 ; n=582)$, non clear-cell histology ( $n=288)$ and with brain metastases $(n=320)$. [36] Patients with poor performance status and brain metastases prior to this had been excluded in all sunitinib trials.

The median number of treatment cycles and treatment duration were 5 cycles and 15.6 months respectively. $56 \%$ of patients received more than 6 months of sunitinib treatment. The survival data closely resembled the phase III study with an observed median PFS and OS of 10.9 months and 18.4 months respectively. [33] No differences were noted in median PFS and OS between patients with or without prior cytokine therapy. Importantly, the subgroup analysis of $i$. elderly patients demonstrated median PFS and OS of 11.3 and 18.2 months respectively. [33] ii. patients with poorer performance status, the median PFS and OS were 5.1 months and 6.7 months respectively and finally in patients with brain metastases with an overall poorer prognosis, a median PFS of 5.6 months and median OS of 9.2 months were observed. [33]

\subsubsection{Sunitinib continuous dosing}

The efficacy of continuous sunitinib dosing was examined in an open-label multicenter phase II trial. [37] In this study 107 patients were randomly assigned to either morning or evening daily dose of $37.5 \mathrm{mg}$ for a median duration of 8.3 months. $43 \%$ of patients had their dose reduced due to grade 3-4 adverse events. The ORR was $20 \%$ with a median duration of 
response of 7.2 months. The median PFS observed was 8.2 months and the OS was 19.8 months. Tolerability and QOL between the morning and evening dose were similar. However, grade 3 diarrhea, fatigue and hand-foot syndrome were more common in the evening dosing patients. The continuous schedule may benefit patients who are not able to tolerate the intermittent sunitinib 50mg regimen. [33]

Another trial assessing continuous vs. intermittent sunitinib dosing was the EFFECT phase II study. In this trial patients with locally recurrent clear-cell RCC or metastatic RCC, treatment naïve patients, were randomly assigned to standard dosing (50mg/day; 4 weeks on, 2 weeks off) and continuous dosing (37.5mg/day). The intermittent schedule when compared with the continuous schedule showed a trend to improved ORR (32.2\% vs. $28.1 \%$; $\mathrm{p}=0.444)$ and median PFS (8.5 months vs. 7.0 months; $\mathrm{p}=0.070)$. No difference were noted between the median OS (23.1 months vs. 23.5 months, $\mathrm{p}=0.615$ ). [38] Interestingly the median OS was lower than the phase III sunitinib vs. INF- $\alpha$ trial which had a median OS of 26 months. The phase III trial had a higher number of patients with better baseline prognostic features (better performance status and more patients had underwent nephrectomy), which may account for better survival results. [33, 38]

\subsubsection{Sorafenib}

Sorafenib (Nexavar, BAY 43-9006) is an oral multi-kinase inhibitor that targets multiple nonreceptor as well as receptor kinases. These include BRAF and CRAF, non-receptor serine threonine kinases which belong to the RAF/Mek/ERK signaling pathway and also receptor tyrosine kinases including VEGFR2, VEGFR3, PDGFR, fetal liver tyrosine kinase 3 (FLT-3)... and c-kit. [2] In a phase II randomized discontinuation trial of patients with metastatic RCC who had failed previous systemic therapies, sorafenib at a dose of $400 \mathrm{mg}$ BD showed significant disease-stabilizing activity. [39] In another phase II trial, patients with metastatic RCC on sorafenib (initial starting dose of $400 \mathrm{mg}$ BD and escalating to $600 \mathrm{mg}$ BD on progression) were compared with INF- $\alpha$ in the first line setting. PFS was similar in both arms, although in the sorafenib arm, patients experienced greater rates of tumour size reduction, superior quality of life and better treatment tolerance. [40] Subsequently in a phase 3 trial (TARGET) 903 patients with metastatic clear-cell RCC who had progressed on previous treatment were randomized to receive either placebo or sorafenib (400mg BD). Compared with the placebo group, the sorafenib group demonstrated a higher ORR (57\% vs. 34\%) and PFS was significantly longer (5.5 months vs. 2.8 months; $\mathrm{HR}=0.44 ; \mathrm{p}<0.01$ ). [41] This improvement was independent of age (over or under 70 years), prognostic risk, prior cytokine therapy, and previous cardiovascular disease. [41] In this trial, patients in the placebo arm crossed over to sorafenib when progression of disease was diagnosed. In the first interim analysis, a trend towards better OS was noted in patients taking sorafenib, and this was unchanged in the final analysis (17.8 vs. 15.2 months, respectively, $\mathrm{HR}=0.88 ; p=0.146)$. [42] After censoring for the patients who had crossed over on progression from the placebo arm, the OS was significantly longer in the sorafenib arm (17.8 vs. 14.3 months; $\mathrm{HR}=0.78 ; p=0.029)$. [41] Sorafenib has also been accessed in a real-world setting through open-label expanded access studies in Europe (The European Advanced Renal Cell Carcinoma Sorafenib (EU-ARCS) and North America 
(NA-ARCCS). Both studies showed that sorafenib provides similar benefits in first- and second- or later line patient populations and the safety profile was similar to that reported in clinical trials. [43-45] Ongoing clinical trials comparing sorafenib with other treatment options in the first line setting are currently being undertaken. [46]

The role of sorafenib as second line treatment for advanced RCC has also generated significant interest. Sorafenib was compared directly with temsirolimus in the INTORSECT trial. [47] This is the first head-to-head trial comparing a VEGF inhibitor to an mTOR inhibitor. This trial enrolled 551 patients with advanced RCC with good performance status who had progressed after first-line sunitinib therapy. The median PFS with temsirolimus was 4.28 months and 3.91 months with sorafenib. The median OS for temsirolimus cohort was 12.7 months compared to 16.6 months in the sorafenib arm. These results highlighted that temsirolimus did not show superiority over sorafenib in the primary end-point of PFS and the secondary end-point of OS. [47] To date, sorafenib is considered a reasonable first-line treatment option especially in elderly patients or patients with cardiovascular diseases or other co-morbidities. [46, 48]

\subsubsection{Pazopanib}

Pazopanib is an oral tyrosine kinase inhibitor that targets VEGF-1, -2, and -3 receptors, PDGF$\alpha$ and $-\beta$ receptors, and c-kit. [49] A phase II study enrolled 225 patients with metastatic RCC: (69\% were treatment naïve, and $31 \%$ had received previous treatment with cytokine- or bevacizumab-containing regimen). In this study, the ORR was 35\%, median duration of response was 68 weeks and median PFS was 52 weeks. This trial showed durable activity and tolerability of pazopanib in patients with advanced RCC. (Hutson et al, 2010) In a phase III study, 435 patients with locally advanced, and/or metastatic RCC were randomized to receive oral pazopanib or placebo ( $54 \%$ were treatment naïve and $46 \%$ were cytokine pretreated). The PFS was significantly prolonged with pazopanib compared with placebo (median PFS 9.2 vs. 4.2 months; $\mathrm{HR}=0.46$; $95 \% \mathrm{CI}, 0.34$ to $0.62 ; \mathrm{p}<0.0001$ ), with similar results shown in both the Treatment naïve subpopulation (median PFS 11.1 v 2.8 months; HR, 0.40; 95\% CI, 0.27 to 0.60; $\mathrm{P}<.0001$ ), and the cytokine-pretreated subpopulation (median PFS, $7.4 \mathrm{v} 4.2$ months; HR, 0.54; $95 \% \mathrm{CI}, 0.35$ to $0.84 ; \mathrm{p}<0.001$ ). In the pazopanib arm, the ORR was $30 \%$ compared with $3 \%$ in the placebo arm $(\mathrm{p}<0.001)$. The median duration of response was longer than 1 year. [50] The final median OS were 22.9 vs. 20.5 months in the pazopanib and placebo arms respectively $(\mathrm{p}=0.224)$. The lack of significant difference could be due to the early, frequent, and prolonged crossover to pazopanib in patients originally randomized to placebo. [50,51] Whilst the role of pazopanib as a frontline agent for metastatic RCC is being established, it remains unclear how it compares with sunitinib in terms of efficacy. This was addressed in an open-label study (COMPARZ) where pazopanib was compared head-to-head with sunitinib in 1100 patients with locally advanced and/or metastatic RCC. Pazopanib demonstrated similar efficacy or non-inferiority to sunitinib in terms of PFS with duration of more than 10 months. Both agents resulted in side-effects, however fatigue and skin ulcers occurred less frequently for pazopanib than with sunitinib. The quality of life (QoL) favoured pazopanib and demonstrated better tolerance for pazopanib than sunitinib. [52] 


\subsubsection{Axitinib}

Axitinib, an oral agent that inhibits VEGF receptor-1, -2 and -3, is active in cytokine-refractory metastatic RCC. Two complete and 21 partial responses (ORR of $44.2 \%$ ) were reported in 52 patients taking axitinib $5 \mathrm{mg}$ twice daily in a second line treatment study. The median response duration was 23 months and median OS was 29.9 months. [53] The 5 year survival rate was $20.6 \%$. The ten patients surviving for more than five years had an ORR of $100 \%$ compared with $30 \%$ in $<5$ year survivors. They took axitinib for longer (median 5.8 years vs. 0.67 years) and were fitter, with baseline ECOG PS of 0 in $80 \%$ of the longer term survivors compared with $53 \%$ in $<5$ year survivors. [54]

In a phase II trial, 213 patients were allocated on axitinib 5mg BD for four weeks, after which some eligible patients were randomly assigned to further stepwise dose titration ( 5 to 7 to $10 \mathrm{mg}$ BD) according to tolerability of either axitinib or placebo. Individuals who did not meet the eligibility criteria were treated in a separate arm without dose titration. [55] The inclusion criteria for randomisation after the initial dose schedule of axitinib for 4 weeks were blood pressure $\leq 150 / 90 \mathrm{mmHg}$ and less or equal to 2 concurrent anti-hypertensive medications. No grade 3 or 4 toxicities from the initial dose and no dose reductions required in the first 4 weeks of axitinib.

The most important outcomes of this study were a higher drug exposure, of more or equal $150 \mathrm{ng}-\mathrm{h} / \mathrm{ml}$ serum concentration, and was associated with a higher RR (59\% vs. 40\%) and an improvement in PFS (14 vs. 11 months). Patients with a higher diastolic blood pressure $(90 \mathrm{mmHg})$ and an increase in diastolic blood pressure on day 15 of the first cycle had better outcomes in ORR and PFS. The final results of this phase II trial are pending and will determine if the titratrion strategy is associated with improved clinical outcomes

In a phase III second line treatment study (AXIS), 723 patients with progressive disease after one first line treatment (sunitinib, bevacizumab, temsirolimus or cytokines) randomly received axitinib at doses titrated from $5 \mathrm{mg}$ up to $10 \mathrm{mg}$ BD or sorafenib 400mg BD. [56] The ORR was $19.4 \%$ for axitinib vs. $9.4 \%$ for sorafenib $(\mathrm{p}=0.0001)$ and a significantly longer median PFS (6.7 versus 4.7 months, $\mathrm{p}<0.0001$ ) was seen in patients on the axitinib arm. In patients who had previously received cytokines PFS with axitinib was 12.1 months vs. 6.5 months with sorafenib, which was significant $(\mathrm{p}<0.0001)$. This also occurred in those having prior sunitinib (4.8 vs. 3.4 months, $\mathrm{p}=0.0107$ ). As part of the same trial, patient-reported kidney specific symptom and function assessments were secondary endpoints. [57] Outcomes were similar for both drugs during treatment, however due to the significantly longer PFS with axitinib, this delayed worsening of the composite endpoint of cancer symptoms, progression or death compared with sorafenib. [56]

\subsection{Anti-VEGF}

\subsubsection{Bevacizumab}

Bevacizumab is a humanized monoclonal antibody that inhibits the VEGF molecule and therefore targeting all the receptor to which it binds. [58] ) A randomized, double-blind, phase 
II trial of 116 patients (placebo controlled, low-dose $3 \mathrm{mg} / \mathrm{kg}$ or high dose $10 \mathrm{mg} / \mathrm{kg}$ ) showed that bevacizumab significantly prolonged the time to progression of disease in patients with metastatic RCC. $[59,60]$

In a phase III trial (AVOREN), 649 patients with previously untreated metastatic RCC were randomized to receive bevacizumab (10 $\mathrm{mg} / \mathrm{kg}$ infusion) and interferon alfa-2a versus placebo and interferon alfa-2a (IFN). A significant improvement in PFS, (10.2 vs. 5.4 months) and also ORR $(31 \%$ vs. $13 \%$, respectively; $\mathrm{p}<0.0001)$ was observed in the bevacizumab arm compared with the IFN- $\alpha$ monotherapy arm. [61] Final OS analysis of this trial showed a trend towards improved OS (Median OS was 23.3 months with bevacizumab plus IFN and 21.3 months with IFN plus placebo). Patients (> 55\%) in both arms received at least one post-protocol antineoplastic treatment, which could confound the OS analysis. [61]

Another concurrent phase III trial (CALGB 90206) but in a non-blinded fashion, randomized 732 patients previously untreated metastatic RCC to receive bevacizumab and IFN- $\alpha$ versus monotherapy with IFN- $\alpha$. In this trial, the median PFS was 8.5 months in patients receiving bevacizumab plus IFN compared with 5.2 months for IFN monotherapy $(p<0.0001)$ and the ORR was similarly higher in the bevacizumab plus IFN arm than in the IFN monotherapy arm (25.5\% vs. $13.1 \%$, respectively; $\mathrm{p}<0.0001)$. [62] Final analysis of this trial showed a median OS time of 18.3 months (95\% CI, 16.5 to 22.5 months) for bevacizumab plus IFN-alpha and 17.4 months (95\% CI, 14.4 to 20.0 months) for IFN-alpha monotherapy (unstratified log-rank p = 0.097) Grade 3 and 4 toxicity (hypertension (HTN), anorexia, fatigue, and proteinuria) were significantly higher in the bevacizumab plus IFN-alpha arm. Patients who developed HTN on bevacizumab plus IFN-alpha had a significantly improved PFS and OS versus patients without HTN. [62]

Both of these trials showed clear benefits in the median PFS arms with an overlapping HR and doubling of PFS when comparing the placebo/IFN- $\alpha$ arm with bevacizumab/IFN- $\alpha$ arm. [63] The effects of crossover to the active bevacizumab arm in the AVOREN trial, as well as the permission of second-line therapies in both trials would account for the dilution of the actual OS benefit in both trials. [63] Based on the results of these trials, regulatory approval of bevacizumab plus IFN in advanced RCC has occurred in Europe in the United States.

\section{3. mTOR inhibitors}

The mammalian target of rapamycin (mTOR) pathway is regulated by the PTEN tumour suppressor gene. It plays a significant role in angiogenesis and regulation of cell cycle. [8] mTOR activity is dependent on different factors, in particular to cellular stresses such as hypoxia, heat shock, oxidative stress, DNA damage and finally a change in the $\mathrm{pH}$ or osmotic cell pressure. [8] The mTOR pathway is downstream to phosphoinositide 3-kinase and akt pathway which is dysregulated in many malignancies. [8, 64] Activation of this pathway promotes mRNA translation and subsequent entry into the $G_{1}$ phase of cell cycle. Another different but important function of mTOR is the production of HIF- $1 \alpha$ which drives angiogenesis, survival and growth of malignant cells. The selective inhibition of this pathway by the mTOR inhibitors is facilitated by binding to the intracellular protein FK506 binding protein 12 (FKBP-12) resulting in inhibition of the kinase activity of the mTOR. [8] There are 
two mTOR inhibitors registered for the treatment of metastatic RCC, namely temsirolimus and everolimus.

\subsubsection{Temsirolimus}

Temsirolimus is an analogue to sirolimus (rapamycin) which has been used with success as an immunosuppressive agent in renal transplantation. [65] Temsirolimus is a parenteral preparation and is administered as a weekly intravenous infusion at $25 \mathrm{mg}$. It is metabolised by CYP3A4 to active metabolite sirolimus and has a half-life of about 9 to 27 hours. [65]

Based on the encouraging results from Phase I and II trials of temsirolimus either alone, or in combination with IFN- $\alpha$, an international multicentre phase III trial was conducted. $[8,66]$ Six hundred and twenty six treatment naïve patients with poor prognostic factors were randomised to temsirolimus ( $25 \mathrm{mg}$ i.v. weekly), IFN- $\alpha\left(3 \times 10^{6}\right.$ units, with an increase to $18 \times 10^{6}$ units s.c. thrice weekly) or the combination of temsirolimus (15 mg weekly) and IFN- $\alpha$ ( $6 \times$ $10^{6}$ thrice weekly). Patients were required to have least three the following 6 predictors short survival: a serum lactate dehydrogenase level of more than 1.5 times the upper limit of the normal range, a hemoglobin level below the lower limit of the normal range; a corrected serum calcium level of more than $10 \mathrm{mg}$ per deciliter ( $2.5 \mathrm{mmol}$ per liter), a time from initial diagnosis of RCC to randomization of less than 1 year, a Karnofsky performance score of 60 or 70, or metastases in multiple organs. An important characteristic of recruitment of this study is the inclusion of up to $20 \%$ of non clear-cell renal cell histological subtype. This is the only randomised study available to date for patients with non clear-cell histology. Patients who received temsirolimus monotherapy had a longer median OS (10.9 vs. 7.3 months; $p=0.008)$ and PFS (3.8 vs. 1.9months; $p<0.001$ ) compared with those who received INF- $\alpha$ alone. [65] Finally those in the combination treatment arm had the most grade 3 or 4 adverse events leading to more dose reductions and delays. The median PFS in the temsirolimus, combination treatment and IFN- $\alpha$ alone were 3.8, 3.7 and 1.9 months, respectively, and the median OS was 10.9 months, 8.4 months and 7.3 months. [65] In this trial, older patients and patients with a higher serum LDH (> 1.5 fold the upper limit of normal) had better OS. [65]

This trial did not address the role of temsirolimus as second-line agent in patients refractory to VGEF therapy. The only published prospective randomised trial looking at this cohort of patients was RECORD-1 which examined everolimus vs. placebo. [67] The data supporting the use of temsirolimus in second line treatment post VEGF agents are all derived from single institution case series which demonstrated only a modest PFS of $\sim 4$ months.

\subsubsection{Everolimus}

Everolimus is an oral mTOR inhibitor. It has activity against advanced clear-cell RCC in patients who have failed sorafenib, sunitinib or both. [67] In a double-blind, placebo controlled phase III trial (RECORD-1, in which 410 patients with advanced clear cell RCC who had progressed after sunitinib, sorafenib or both were randomized in a 2:1 ratio to everolimus 10 mg once daily or placebo with best supportive care. Independent of gender, age, previous treatment with sorafenib, sunitinib or both, prolongation of PFS (4.9 vs. 1.9 months; $p<0.0001$ ) 
was found with everolimus over placebo. [67] However there was no statistically significant difference for median OS (14.8 months vs. 14.4 months) as majority (80\%) of patients in the placebo plus best supportive arm were allowed to cross over after the unbinding at the second interim analysis. RECORD-1 trial proved the efficacy of mTOR inhibitors following VGEF therapy and as such received FDA approval for patients who have progressed following sunitinib / sorafenib. [67]

\section{New agents in clinical development}

The results with early TKIs in metastatic RCC has led to a number of small molecules multitargeted agents being investigated in phase II and III studies. [68] These include tivozanib which targets VEGFR -1, -2, and -3, PDGFR and c-kit, dovitinib (VEGFR -1, -2, -3 and PDGFRbeta) and regorafenib. [69]

\subsection{Tivozanib}

In a phase II study, two hundred and seventy two patients with advanced RCC treated who had not received prior VEGF targeted therapy received tivozanib. [70] Patients took tivozanib $1.5 \mathrm{mg}$ daily for 16 weeks, and according to response were then stratified into stopping or continuing tivozanib. Those with stable disease were randomised between tivozanib and placebo (and this group could re-start tivozanib if they developed progressive disease, or completed the double blind phase). Overall, by week $16,84 \%$ of patients demonstrated PR or $\mathrm{SD}$, ORR was 30\%, disease control rate (DCR) was 85\% and median PFS 11.7 months. Best results were achieved in patients with clear-cell histology who had undergone a nephrectomy. These patients achieved an ORR of $36 \%$, DCR of $88 \%$ and median PFS of 14.8 months. Commonest adverse effects included hypertension (45\%) which was grade $3-4$ in $12 \%$, and dysphonia (22\%). [70]

Twenty-eight patients with advanced RCC and clear-cell variant, who had failed up to one prior VEGF-targeted therapy, were treated in a phase Ib open-label study of tivozanib combined with temsirolimus. [71] Tivozanib was administered orally daily for 3 weeks on and 1 week off. Intravenous temsirolimus was given once weekly. A standard 3+3 dose escalation design was used at four levels from $0.5 \mathrm{mg}$ to $1.5 \mathrm{mg}$ per day and 15 to $25 \mathrm{mg}$ per week of tivozanib and temsirolimus, respectively. Twenty-eight patients ( 26 male) of median age 62 years and Karnofsky Performance Status from 100 to 80 were participated in the study. Median duration of treatment was 21.1 weeks. PR was seen in $28 \%$, SD in $64 \%$ and DCR (PR and SD > 24 weeks) in $48 \%$ of the treated population. Treatment-related adverse events seen in $\geq 10 \%$ of patients were: fatigue, decreased appetite, stomatitis, thrombocytopenia, diarrhea, nausea, constipation and dyspnea. There were no grade 4 events, and no dose limiting toxicities. [71]

Preliminary results of a phase III trial comparing tivozanib to sorafenib in stage IV RCC as first line treatment were made available at the ASCO 2012 annual meeting. [72] Tivozanib in comparison with sorefenib resulted in an improvement in PFS (HR 0.80; median 12 vs. 10 months respectively; $\mathrm{p}=0.04$ ) and higher ORR (33 vs. 23\%). Patients on tivozanib experienced 
a higher incidence of grade 3 or 4 hypertension ( $26 \mathrm{vs.} 17 \%$ ), higher rates of dysphonia (21 vs. $5 \%$ ) and back pain (14 vs. $7 \%$ ). However, tivozanib had less diarrhea (24 vs. $38 \%$ ), hand and foot syndrome (15 vs. $71 \%$ ) and alopecia (2 vs. $21 \%$ ). [72]

\subsection{Dovitinib}

The highest tolerated dose of dovitinib is $500 \mathrm{mg}$ daily on a 5-day on/ 2 day off schedule in 28day cycles. A phase II study of dovitinib in clear-cell metastatic RCC and in patients previously treated with a VEGFR inhibitor and/or mTOR inhibitor was reported in 2011. [73] In 51 patients overall responses were PR in 8\%, and SD $\geq 4$ months in 37\%. Median PFS and OS were 6.1 and 16 months respectively. The most common adverse events were nausea (73\%; grade 3:9\%), diarrhea (64\%; grade 3:9\%), vomiting (56\%; grade 3:5\%), decreased appetite (48\%; grade 3:7\%), asthenia (36\%; grade 3:12\%), and fatigue (36\%; grade 3: $10 \%)$. An on-going phase 3 trials is comparing dovitinib with sorafenib in patients who have had one previous VEGF- and mTORtargeted therapy.

\subsection{Regorafenib}

A phase II of regorafenib in previously untreated metastatic or unresectable RCC patients has recently been published. [69]. Forty-eight of 49 patients enrolled were available for assessment of tumour response. Nineteen of these had an objective response (partial); $(39.6 \%, 90 \% \mathrm{CI}$ 27.7-52.5). Side-effects were noted in $98 \%$ of patients, and $35 \%$ experienced serious drugrelated events. Two patients had grade 4 adverse events related to treatment including two cardiac ischaemia or infraction, one hypomagnesaemia, and one chest/thoracic pain. The authors advise close monitoring. [69]

\section{Combination therapy in metastatic RCC}

With the increasing use of VEGF and mTOR inhibitors, it has been noted that patients eventually develop resistance / relapse after 6 months to 3 years of therapy. [25] This has been the driving force for the development of more novel anti-angiogenic agents or treatment strategies such as combination of the various targeted agents (combination of antiangiogenic agents or with mTOR inhibitors, chemotherapy or immunotherapy). [74] Combination therapies may lead to a more complete blockade of aberrant signaling and potentially delay / prevent the development of resistance observed with single-agent treatment. [74] Unfortunately, this invariably leads to increased toxicities as experienced in some of the phase I trials. [75]

\subsection{VEGF-ligands or receptor inhibitors / mTOR plus immunotherapy combination}

Two single arm phase II studies using sorafenib in combination with standard dose IFN- $\alpha$ showed higher ORR (approximately 30\%) and longer PFS (7 - 12 months) when compared with phase III data of sorafenib monotherapy. [76, 77] However, in a randomized phase II trial 
of sorafenib vs. sorafenib and low-dose IFN- $\alpha$ in patients with advanced RCC, no statistically significant difference in ORR and PFS was noted in the two arms. [78] These results should be interpreted cautiously given the small number of patients in these studies. [78]

Both AVOREN $(\mathrm{n}=649)$ [79] and CALGB $90206(\mathrm{n}=732)$ [80] compared bevacizumab / IFN$\alpha$ combination with IFN- $\alpha$ demonstrated that the PFS interval was significantly longer with bevacizumab plus IFN- $\alpha$ than with the IFN- $\alpha$ alone (AVOREN: 10.2 months versus 5.4 months, respectively; $\mathrm{p}=0.0001$; CALGB 90206: 8.5 months versus 5.2 months, respectively; $\mathrm{p}<0.0001$ ). The ORRs were $31 \%$ with bevacizumab plus IFN- $\alpha$ and $13 \%$ with placebo plus IFN- $\alpha$ (p = 0.0001) in the AVOREN study. In the CALGB 90206 trial, the ORRs were $25.5 \%$ with bevacizumab plus IFN- $\alpha$ and $13.1 \%$ with IFN- $\alpha$ ( $p<0.0001)$. [74, 79, 80] The design of these trials however did not have a bevacizumab monotherapy arm and therefore the clinical efficacy of bevacizumab monotherapy remained unanswered. In an open-label phase 2 study (TORAVA), 171 patients with metastatic RCC were randomly assigned (2:1:1) to receive the combination of bevacizumab (10 mg/kg every 2 weeks) and temsirolimus ( $25 \mathrm{mg}$ weekly) or sunitinib (50 $\mathrm{mg} /$ day for 4 weeks followed by 2 weeks off) or the combination of IFN- $\alpha\left(9 \times 10_{6}\right.$ IU three times per week) and bevacizumab (10 mg/kg every 2 weeks). PFS at 48 weeks was $29.5 \%$ (26 of 88 patients, $95 \%$ CI 20.0-39.1) in group A, 35.7\% (15 of 42, 21.2-50.2) in group B, and $61.0 \%$ ( 25 of 41, 46.0-75.9) in group C. Median PFS was 8.2 months (95\% CI 7.0-9.6) in group A, 8.2 months (5.5-11.7) in group B, and 16.8 months (6.0-26.0) in group C. The toxicity of the experimental regimen was high with over $50 \%$ of patients not able to tolerate the combination of bevacizumab and temsirolimus over several months. This combination failed to show any beneficial activity and was more toxic than the treatments used in the other arms, and therefore was not recommended as first line treatment in these patients. [81]

The combination of temsirolimus and IFN- $\alpha$ was studied in a phase III trial. Six hundred and twenty six patients were randomized to receive of IFN- $\alpha$ alone, temsirolimus alone, or a combination of the two drugs. Median OS times in the IFN- $\alpha$ arm, the temsirolimus arm, and the combination-therapy arm were $7.3,10.9$, and 8.4 months, respectively. Unlike temsirolimus alone, the combination of temsirolimus plus IFN- $\alpha$ did not improve OS. Therefore the temsirolimus / IFN- $\alpha$ combination is not recommended as standard practice for treatment of advanced RCC. [65]

Lastly, in a global, open-labelled multi-centre phase IIIb trial (INTORACT), temsirolimus and bevacizumab was compared with interferon and bevacizumab as first-line treatment in 791 patients with predominantly clear-cell metastatic RCC. [82] At the interim analysis, 489 patients were assessed PFS events. Median PFS with temsirolimus / bevacizumab combination was 9.1 month compared to 9.3 months in the interferon / bevacizumab group. The median OS was 25.8 months in the temsirolimus and 25.5 months for the interferon group. [82]

\subsection{VEGF-ligands or receptor inhibitors / mTOR combination}

Bevacizumab in combination with sorafenib and sunitinib has been evaluated in two phase I trials. In these trials although there were some promising results regarding the median time to progression and partial response rates in the combination arms, the adverse effects observed in the latter were prominent. [83, 84] The combination arm in both trials required dose 
reduction of both agents and resulted in a considerably lower maximum tolerated dose in contrast to the maximal tolerated dose of the single agent. Bevacizumab potentiated the sideeffects of sorafenib such as hypertension and hand-foot syndrome; hematological, vascular toxicities (including microangiopathic hemolytic anaemia) and hypertension in the sunitinib combination. [75] Finally, a phase II study assessing the tolerability and efficacy of multiple combinations of currently available therapies, is being processed in the Eastern Cooperative Oncology BeST trial. The four arms are bevacizumab $(10 \mathrm{mg} / \mathrm{kg})$, bevacizumab $(5 \mathrm{mg} / \mathrm{kg}) /$ temsirolimus ( $25 \mathrm{mg}$ ), bevacizumab ( $5 \mathrm{mg} / \mathrm{kg}$ ) and sorafenib (200mg twice daily)/ temsirolimus (25mg). [85]. The results are currently pending.

\section{Sequencing therapy in metastatic RCC}

Sequential use of targeted agents has several potential benefits. Firstly, this approach could lead to a treatment continuum, secondly, it provides patients the opportunity to receive full doses of the targeted agents without affecting tolerability and finally, sequential targeting of different molecular pathways could potentially overcome any resistance that would arise from single target inhibition. [86]

\subsection{Anti-angiogenic therapy after immunotherapy}

Few phase II trials using anti-angiogenic agents after progression on immunotherapy lead to promising results. $[32,59,87]$ In a phase III trial (TARGET) patient who had progressed on cytokine therapy after receiving sorafenib, there was a notable doubling of PFS from 2.8 to 5.6 months. [41] Likewise, the utilization of axitinib post progression on cytokine in a phase II trial, lead to a TTP of 15.7 months. [77] There are no head-to-head data present to guide which agent is best utilized post cytokine therapy and a properly conducted phase III trial are required to share further insight into this treatment strategy.

\section{2. mTOR blockade after anti-angiogenic therapy}

In this strategy, the RECORD-1 trial investigated the efficacy of everolimus vs. placebo with best supportive care post progression on sunitinib, sorafenib or both. Seventy one per cent of patients included in the trial had received prior sunitinib treatment and 55\% sorafenib therapy. Patient on everolimus achieved addition of 3-month in terms of PFS regardless of prior treatment. No overall survival benefit was observed due to large numbers of cross over from placebo to everolimus arm (80\%). [67]

RECORD-3, a phase III clinical trial recently closed to patient recruitment, randomly assigned patients to either everolimus or sunitinib. Upon first sign of progression, patients would cross over to sunitinib if they were on everolimus and to everolimus if previously on sunitinib. The primary end point of this trial was to evaluate whether PFS post first-line treatment for patients who received everolimus will be non-inferior to patients who receive sunitinib. [52] 


\subsection{Serial anti-angiogenic agents}

With the availability of multiple SMTKIs, an important focus ahead is in the identification of how to best utilize the TKIs in sequence. There is now increasing evidence supporting the sequential use of VEGF-targeted therapies.

In both phase II and III trials, axitinib has shown encouraging results in second-line setting in advanced RCC. [88] In an ongoing study, the Sequential Two-agent Assessment in Renal Cell Carcinoma Therapy (START), two hundred and forty treatment-naïve patients with clear-cell component metastatic RCC will be randomized into 6 arms to receive different 2-drug "sequences" of everolimus, bevacizumab, or pazopanib. The primary end point is the detection of the longest combination of the TTP. [89]

A retrospective study on RCC patients treated with sunitinib and sorafenib evaluated the effectiveness of switching from one TKI agent to the other after disease progression. In this study patients who received sunitinib followed by sorafenib experienced a shorter time to progression than patients who received sorafenib followed by sunitinib (risk ratio (RR) 3.0; $p$ $=0.016$ ). Similarly, the median OS was 102 weeks in patients who received sorafenib followed by sunitinib compared with 45 weeks in patients who received sunitinib followed by sorafenib $(\mathrm{p}=0.061) \cdot[90]$

An ongoing phase III trial (SWITCH trial) is currently being undertaken comparing sorafenib until progression followed by sunitinib and sunitinib until progression followed by sorafenib in the first line advanced RCC setting. The primary end point is the PFS and hopefully this trial will show further insight into which anti-VEGF treatment sequence will confer better clinical outcome in patients with metastatic RCC. [91]

\section{Systemic treatment for non-clear cell renal cell carcinoma}

With clear-cell RCC being the predominant histological subtypes and non clear-cell (papillary and chromophobe) being represented only in $\sim 10 \%$ of clinical trials, there is consequently a paucity of data regarding treatment for advance non-clear-cell RCC. [92] Novel target therapies have demonstrated promising results in clear-cell histologies, however their activities remained undefined in the non-clear-cell counterpart. Majority of the data is derived from expanded access trials, retrospective series, and subset analyses of major trials. [93] Patients with non clear-cell RCC were both excluded from the landmark phase III trials of sunitinib and sorafenib. The largest non clear-cell series were derived from the sunitinib and sorafenib expanded access trials, which allowed entry of non-clear-cell histologies. Gore and colleagues demonstrated sunitinib activity in the multi-centre, international, non-randomised expanded access compassionate trial. Of the 4500 patients enrolled, approximately $10 \%(n=437)$ had non clear-cell histology (not further characterized) were evaluated. An ORR of $11 \%$ was demonstrated $(\mathrm{N}=48)$ with 46 partial responders and 2 complete responders. Fifty sever percent had stable disease $(\mathrm{N}=250)$ for a t least 3 months. [36] The median OS was reported as 13.4 months. The ORR was notable lower, $11 \%$ compared to the reported 42 to $47 \%$ in the phase III trial. The 
non-stringent reporting of disease progression and the reliance of local practice may well account for the discrepancy in the results.

The Advanced Renal Cell Carcinoma Sorafenib (ARCS) expanded access trial recruited patient with advanced RCC who were not eligible for other clinical trials. One hundred and fifty eight patients with papillary RCC were enrolled. Partial response of $3.4 \%$ and $5.6 \%$ were noted for patients with papillary and chromophobe RCC respectively. Eighty-seven patients $(77.1 \%$ of the papillary RCC and $88.8 \%$ of the chromophobe RCC) demonstrated disease stability for a duration of more than 8 weeks. Despite only modest activity being noted, this trial has at least shared insight into the activity of sorafenib into the two most common non clear-cell variant. [44] Another trial that demonstrated TKI activity across the different histological subtypes were reported in a retrospective analysis of patients with metastatic papillary and chromophobe RCC who received either sunitinib and sorafenib as their initial frontline therapy. The reported ORR, PFS and OS were 10\%, 8.9 months and 12.2 months respectively. A sub-analysis revealed a longer higher response rate for chromophobe variant (25\%) compared to papillary variant $(4.8 \%) ;(\mathrm{p}=0.007)$. Similarly the PFS in the chromophobe population was longer $(9.3$ months) when compared with papillary population 6.6 months $(p=0.07)$. There were no differences between the OS across both histologies. When stratified according to TKI type, the papillary population had a statistically longer PFS (11.9 months) with sunitinib compared to sorafenib (5.1 months; $\mathrm{p}<0.001)$. [3]

Temsirolimus has demonstrated promising activity in both clear-cell and non-clear-cell RCC. The phase III trial undertaken by Hudes and colleagues, examined the efficacy of temsirolimus, IFN- $\alpha$ or combination of both in patients with poor MSKCC prognostic features. [65] Although majority of patients had clear-cell histology, approximately $20 \%$ of non-clear-cell variant were included in the clinical trial. An improvement in median OS and median PFS were seen in temsirolimus arm, across all histologies with a significant advantage in hazard ratio for OS in the temsirolimus. An updated sub-analysis of the study showed a hazard ratio of 0.55 and 0.36 for median OS and PFS respectively, clearly favouring temsirolimus over IFN- $\alpha$ monotherapy and IFN- $\alpha$ / temsirolimus combination arms. [94] The analysis also showed that $75 \%$ of the non clear-cell variant consisted of papillary subtype. This has led to subsequent FDA approval of temsirolimus as treatment for non-clear-cell histology in advanced RCC.

Everolimus through RECORD-1 trial has reported efficacy in patient who progressed on one or two line of TKI. This has led to the development of an open-label, single arm, multi-centre phase II examining the efficacy of everolimus as first-line systemic therapy for patients with advanced papillary RCC. [8] This trial will stratify the histology into type I and II, and recruitment will hopefully show further insight into the treatment of papillary variant of RCC.

Epidermal growth factor receptor (EGFR) has been investigated as potential therapeutic target in metastatic RCC. Erlotinib, an anti-EGFR was examined in a phase II study of treatment naïve patients with locally advanced or metastatic papillary RCC. [95] Fifty two patients were registered and 45 were evaluable. The ORR was reported as $11 \%$ and the disease control rate was $64 \%$ with 5 partial responders and 24 patients with stable disease. The six month PFS was $30 \%$ and median survival of 27 months was documented. [95] 
Collecting duct tumour is a very aggressive but rare variant of aggressive but rare variant of RCC. The largest data is derived from a phase II multi-centre trial of 23 treatment naïve patients who received platinum based chemotherapy with gemcitabine. The choice of chemotherapy is that of a platinum doublet based on some similarities to transitional cell carcinoma of the bladder. The ORR was $26 \%$ with a median PFS and OS of 7.1 months and 10.5 months respectively.[18] There is no data to support the use of TKI in this variant of tumour.

\section{Side effects of targeted therapies used in renal cell carcinoma}

The increasing use of novel anti-VEGF agents, and for longer periods of time for the treatment of RCC has raised challenges in the management of the associated toxicities or adverse effects. There are supportive interventions developed for their prevention and control. [96]

It has been identified in clinical trials and post marketing surveillance that the treatment toxicities associated with the new targeted therapies against cancer differ significantly from the toxicities seen with conventional chemotherapy. [96, 97]

Many of the anti-VEGF agents share similar toxicities, including hypertension, fatigue, gastrointestinal, skin and bone marrow effects. The mTOR inhibitors have unique adverse effects, which include metabolic alterations (hypercholesterolnaemia, hyperglycermia), gastrointestinal alterations and interstitial pneumonitis. Hypothyroidism is seen uniquely in patients on sunitinib, potentially sorafenib and pazopanib. [96]

\subsection{Hyperension}

Arterial hypertension is commonly observed as an adverse event in patients treated with inhibitors of the VEGF pathway. [96, 98] The most common implicated anti-VEGF agents include axitinib, bevacizumab, sorafenib, sunitinib and pazopanib. [33, 41, 51, 99, 100] Prompt identification of arterial hypertension is essential to prevent serious consequences such as strokes and heart failure. [101, 102] The regular use of ambulatory BP monitoring may be valuable for early detection and accurate assessment of blood pressure (BP) changes. [103] Hypertension has occurred whether or not the patient has a history of high blood pressure, however incidence may be higher in patients with pre-existing cardiovascular disease. [33, 41, 50, 99] There are pre-existing algorithms to treat hypertension associated with targeted therapies [96] but it falls on the clinician's discretion to individualise treatment accordingly. [98] For example, the use of angiotensin-converting enzyme (ACE) inhibitor is a logical choice if bevacizumab is the underlying cause as they may improve the associated proteinuria. [104] Angiotensin II inhibitors, diuretics, dihydropyridine calcium channel blockers (CCBs), and $\beta$ blockers are also considered as appropriate anti-hypertensive agents.

\subsubsection{Hypertension as a biomarker}

Hypertension induced by sunitinib and bevacizumab is associated with improved clinical outcomes, supporting its use as an efficacious biomarker. In a retrospective analysis which 
included pooled efficacy and safety data $(n=544, n=4917)$ from four trials of patients with metastatic RCC treated with sunitinib 50mg/d (4 week on / 2 week off), it was observed that patients who had a systolic BP $\geq$ to $140 \mathrm{mmHg}$ and a diastolic blood pressure of $\geq 90 \mathrm{mmHg}$ had better outcomes compared to those without treatment induced hypertension The ORR were $54.8 \%$ in the treatment induced hypertension cohort vs. $8.7 \%$ in the normotensive patients. The median PFS was 12.5 vs. 2.5 months in the hypertensive and normotensive respectively and similarly the median OS was 30.9 months in the hypertensive group vs. 7.2 months in the normotensive group. [105] The rates of AEs were similar between patients with and without hypertension. However patients with high BP experienced more frequent renal adverse events (5\% vs. 3\%). [105] More importantly, no difference in outcome (PFS and ORR) was noted regardless of whether patients received treatment for their hypertension. [105]

Treatment induced arterial hypertension is also correlated with good clinical outcomes in patients treated with bevacizumab for metastatic colorectal cancer [106] but this has not been investigated widely in metastatic RCC.

\subsection{Fatigue}

Fatigue is a very frequent side-effect seen with the targeted agents used in metastatic RCC [74, $96,107]$ The incidence of fatigue in phase III studies ranged from $14 \%$ to $51 \%$ for all grades and up to $11 \%$ for grade $3-4$.

There is no direct treatment available to alleviate treatment induced fatigue. Monitoring and treating patients for any aggravating or reversible factors (i.e. anaemia, anxiety, hypothyroidism, depression may help. If grade 3-4 fatigue persists, dose reduction or cessation of the treatment should be considered. $[96,108]$

\subsubsection{Fatigue as a biomarker}

Fatigue is another potential biomarker in patients with metastatic RCC treated with sunitinib. A retrospective analysis of pooled data from 770 patients who received sunitinib in 5 clinical trials for metastatic RCC revealed that the development of grade 1-2 fatigue was linked with significantly longer time to progression and improved overall survival. [109]

\subsection{Hand and foot syndrome as biomarker}

In a retrospective registry of metastatic RCC, 705 and 365 patients treated with sunitinib and sorafenib respectively were assessed for outcomes of the disease in those who developed hand and foot syndrome. In the sunitinib group, the median OS was 43 months for those with the hand and foot syndrome vs. 31 months $(\mathrm{p}=0.027)$ in those without. The PFS in patients with the dermatological toxicity was 20.8 months vs. 11.1 months $(p=0.007)$ in those without. In the sorafenib group, no differences was noted in median OS for those that did and did not experience hand foot syndrome ( 27.9 vs. 24.6 months ( $p=0.244)$. The PFS was 12.2 vs. 8.8 months $(\mathrm{p}=0.050)$ with a difference of 3.4 months in those that experienced hand foot syndrome. In multivariable cox regression analysis, hand and foot syndrome was associated with longer OS in the sunitinib group. In sorafenib, the survival benefits were less convincing. [110] 


\subsection{Other biomarkers}

Emerging data has also shown that other adverse effects such as hypothyroidism, myelosuppression in addition to the aforementioned hypertension and hand foot syndrome were biomarkers for tumour control and OS when sunitinib is the agent in use. [111, 112] In mTOR inhibitors, serum LDH, elevated cholesterol and pneumonitis have been studied as predictive biomarkers. [113-115]

\section{Quality of life in patients with renal cell carcinoma receiving targeted}

\subsection{Therapy}

Quality of life (QoL) has been evaluated in a series of trials of patients taking novel targeted agents for RCC. Questionnaires used have included the Functional Assessment of Cancer Therapy-General (FACT-G), the FACT Kidney Symptom Index-15 item (FKSI-15), the FACTKidney Symptom Index-Disease related Symptoms (FKSI-DRS), the European Organization for Research and Treatment of Cancer Quality of Life Questionnaire (EORTC QLQ-C30 and the Euro QOL 5D (Index and Visual Analogue Scale) utility score (EQ-5D) Index.

One of the important outcomes was that newer treatment approaches may be better tolerated with improved QOL compared to the older generation agents. Sunitinib has shown meaningful differences, both in kidney cancer related symptoms and overall QOL over IFN- $\alpha$. [33] This is not unexpected given the more difficult toxicity profile of sunitinib.

Sorafenib, on the contrary revealed no worst QoL score based on the FACT-G or FKSI-15 undertaken in the TARGET trial. On the other hand, targeted therapies compared to placebo were not revealing worse scores in the QOL questioners. Interestingly, qualitative assessment of one's ability to enjoy life, concerns for well-being, fevers, dyspnea and cough were reported less in the patients on sorafenib. [116]

Pazopanib unexpectedly did not have a clinically different QoL compared with placebo, despite the adverse events that a clinician may expect with pazopanib. [50, 100]

In the AXIS trial where axitinib was compared head-to-head with sorafenib, patient-reported kidney-specific symptom and function assessments were secondary endpoints that were examined. [57] Overall, patients on the axitinib treatment arm reported comparable outcomes to that of sorafenib. The PFS benefit seen by axitinib is associated with a delay in worsening of the composite end point of advanced RCC symptoms, progression, or death with sorafenib. [57]

PSICES is a small but important randomized trial comparing patient's preference for pazopanib or sunitinib for first-line treatment of metastatic RCC. The rationale of this trial was to select the more tolerable agent with the recent approval of numerous TKIs as front-line agents. [117] One hundred and sixty nine patients with metastatic RCC were randomly assigned to blinded treatment of pazopanib for 10 weeks with a wash out prior to $50 \mathrm{mg}$ of sunitinib for 10 weeks, and vice versa ( 4 weeks of sunitinib followed by 2 weeks break before 10 weeks of pazopanib). Fifty four and sixty patients first received pazopanib and sunitinib respectively. The patience 
preference when assessed at 22 weeks revealed $70 \%$ of patients preferred pazopanib, $22 \%$ preferred sunitinib, and $8 \%$ expressed no preference. The magnitude of difference was $49.3 \%$ between pazopanib and sunitinib. Fewer patients received pazopanib required a dose reduction (13\% vs. $20 \%)$, prematurely discontinued treatment during the first study period (14\% vs. $8 \%)$, or prematurely discontinued treatment during the second period $(15 \%$ vs. $31 \%)$. $[117,118]$

\section{Conclusion}

The discovery of anti-angiogenic (small molecule tyrosine kinase inhibitors and anti-VEGF agents) agents has altered the treatment landscape for patients with metastatic RCC. Their effective anti-neoplastic activities have provided hope of survival beyond six month, in contrast to that traditionally gained from IFN- $\alpha$ therapy. Different treatment strategies are being investigated vigorously, either in combination or in sequence with the aim of improving the pre-existing survival and response rates. Whilst the treatment algorithm for advanced clear-cell variant of renal cell carcinoma is constantly evolving with increasing treatment options, the non clear-cell counterpart remains an area in need of significant research. With improved understanding of the various molecular pathways, options for non clear-cell variants would hopefully become more established. The recognition of the potentially serious side-effects of targeted agents begs for vigilance in the clinician's part to improve treatment adherence and compliance. Close monitoring of these toxicities will also allow for better identification of their role as bio-markers of efficacy. The ultimate goal is to have an effective agent that leads to durable response with a tolerable side-effect profile.

\section{Acknowledgements}

We wish to express our gratitude to Ms. Judith Lees, Senior Cancer Pharmacist, RAH Cancer Centre, for assistance with new drugs information.

\section{Author details}

Thean Hsiang Tan, Sina Vatandoust and Michail Charakidis

RAH Cancer Centre, Royal Adelaide Hospital, Adelaide, Australia

\section{References}

[1] Cohen HT, McGovern FJ. Renal-cell carcinoma. N Engl J Med. 2005 Dec 8;353(23): 2477-90 
[2] Wilhelm SM, Adnane L, Newell P, Villanueva A, Llovet JM, Lynch M. Preclinical overview of sorafenib, a multikinase inhibitor that targets both Raf and VEGF and PDGF receptor tyrosine kinase signaling. Mol Cancer Ther. 2008 Oct;7(10):3129-40

[3] Choueiri TK, Plantade A, Elson P, Negrier S, Ravaud A, Oudard S, et al. Efficacy of sunitinib and sorafenib in metastatic papillary and chromophobe renal cell carcinoma. J Clin Oncol. 2008 Jan 1;26(1):127-31

[4] Haase VH. Renal cancer: oxygen meets metabolism. Exp Cell Res. 2012 May 15;318(9):1057-67

[5] Ohh M, Park CW, Ivan M, Hoffman MA, Kim TY, Huang LE, et al. Ubiquitination of hypoxia-inducible factor requires direct binding to the beta-domain of the von Hippel-Lindau protein. Nat Cell Biol. 2000 Jul;2(7):423-7

[6] Kamura T, Sato S, Iwai K, Czyzyk-Krzeska M, Conaway RC, Conaway JW. Activation of HIF1alpha ubiquitination by a reconstituted von Hippel-Lindau (VHL) tumor suppressor complex. Proc Natl Acad Sci U S A. 2000 Sep 12;97(19):10430-5

[7] Maxwell PH, Wiesener MS, Chang GW, Clifford SC, Vaux EC, Cockman ME, et al. The tumour suppressor protein VHL targets hypoxia-inducible factors for oxygendependent proteolysis. Nature. 1999 May 20;399(6733):271-5

[8] Amato R. Everolimus for the treatment of advanced renal cell carcinoma. Expert Opin Pharmacother. 2011 May;12(7):1143-55

[9] Kim WY, Kaelin WG. Role of VHL gene mutation in human cancer. J Clin Oncol. 2004 Dec 15;22(24):4991-5004

[10] Vaupel P. The role of hypoxia-induced factors in tumor progression. Oncologist. 2004;9 Suppl 5:10-7

[11] Beck SD, Patel MI, Snyder ME, Kattan MW, Motzer RJ, Reuter VE, et al. Effect of papillary and chromophobe cell type on disease-free survival after nephrectomy for renal cell carcinoma. Ann Surg Oncol. 2004 Jan;11(1):71-7

[12] Furge KA, MacKeigan JP, Teh BT. Kinase targets in renal-cell carcinomas: reassessing the old and discovering the new. Lancet Oncol. 2010 Jun;11(6):571-8

[13] Choi JS, Kim MK, Seo JW, Choi YL, Kim DH, Chun YK, et al. MET expression in sporadic renal cell carcinomas. J Korean Med Sci. 2006 Aug;21(4):672-7

[14] Linehan WM, Pinto PA, Srinivasan R, Merino M, Choyke P, Choyke L, et al. Identification of the genes for kidney cancer: opportunity for disease-specific targeted therapeutics. Clin Cancer Res. 2007 Jan 15;13(2 Pt 2):671s-9s

[15] Isaacs JS, Jung YJ, Mole DR, Lee S, Torres-Cabala C, Chung YL, et al. HIF overexpression correlates with biallelic loss of fumarate hydratase in renal cancer: novel role of fumarate in regulation of HIF stability. Cancer Cell. 2005 Aug;8(2):143-53 
[16] Pavlovich CP, Walther MM, Eyler RA, Hewitt SM, Zbar B, Linehan WM, et al. Renal tumors in the Birt-Hogg-Dube syndrome. Am J Surg Pathol. 2002 Dec;26(12):1542-52

[17] Yamazaki K, Sakamoto M, Ohta T, Kanai Y, Ohki M, Hirohashi S. Overexpression of KIT in chromophobe renal cell carcinoma. Oncogene. 2003 Feb 13;22(6):847-52

[18] Oudard S, Banu E, Vieillefond A, Fournier L, Priou F, Medioni J, et al. Prospective multicenter phase II study of gemcitabine plus platinum salt for metastatic collecting duct carcinoma: results of a GETUG (Groupe d'Etudes des Tumeurs Uro-Genitales) study. J Urol. 2007 May;177(5):1698-702

[19] National Comprehensive Cancer Network guidelines 1.2012 kidney cancer. Available from: http://wwwnccnorg/professionals/physician_gls/defaultasp.Accessed February 1,2012

[20] Posadas EM, Figlin RA. Systemic therapy in Renal Cell Carcinoma: Advancing Paradigms. Oncology. 2012;26(3):1-18

[21] Yagoda A, Bander NH. Failure of cytotoxic chemotherapy, 1983-1988, and the emerging role of monoclonal antibodies for renal cancer. Urol Int. 1989;44(6):338-45

[22] Motzer RJ, Bander NH, Nanus DM. Renal-cell carcinoma. N Engl J Med. 1996 Sep 19;335(12):865-75

[23] Fyfe G, Fisher RI, Rosenberg SA, Sznol M, Parkinson DR, Louie AC. Results of treatment of 255 patients with metastatic renal cell carcinoma who received high-dose recombinant interleukin-2 therapy. J Clin Oncol. 1995;13:688-96

[24] Tan TH, Pranavan G, Haxhimolla HZ, Yip D. New systemic treatment options for metastatic renal-cell carcinoma in the era of targeted therapies. Asia Pac J Clin Oncol. 2010 Mar;6(1):5-18

[25] Jonasch E, Hutson TE, Harshman LC, Srinivas S. Advanced Renal Cell Carcinoma: Overview of Drug Therapy fro the Practicing Physician. J Clin Oncol. 2011;ASCO Education Book:145-51

[26] Abrams TJ, Murray LJ, Pesenti E, Holway VW, Colombo T, Lee LB, et al. Preclinical evaluation of the tyrosine kinase inhibitor SU11248 as a single agent and in combination with "standard of care" therapeutic agents for the treatment of breast cancer. Mol Cancer Ther. 2003 Oct;2(10):1011-21

[27] Kim DW, Jo YS, Jung HS, Chung HK, Song JH, Park KC, et al. An orally administered multitarget tyrosine kinase inhibitor, SU11248, is a novel potent inhibitor of thyroid oncogenic RET/papillary thyroid cancer kinases. J Clin Endocrinol Metab. 2006 Oct;91(10):4070-6

[28] Mendel DB, Laird AD, Xin X, Louie SG, Christensen JG, Li G, et al. In vivo antitumor activity of SU11248, a novel tyrosine kinase inhibitor targeting vascular endothelial 
growth factor and platelet-derived growth factor receptors: determination of a pharmacokinetic/pharmacodynamic relationship. Clin Cancer Res. 2003 Jan;9(1):327-37

[29] Murray LJ, Abrams TJ, Long KR, Ngai TJ, Olson LM, Hong W, et al. SU11248 inhibits tumor growth and CSF-1R-dependent osteolysis in an experimental breast cancer bone metastasis model. Clin Exp Metastasis. 2003;20(8):757-66

[30] Faivre S, Delbaldo C, Vera K, Robert C, Lozahic S, Lassau N, et al. Safety, pharmacokinetic, and antitumor activity of SU11248, a novel oral multitarget tyrosine kinase inhibitor, in patients with cancer. J Clin Oncol. 2006 Jan 1;24(1):25-35

[31] Motzer RJ, Bukowski RM. Targeted therapy for metastatic renal cell carcinoma. J Clin Oncol. 2006;24:5601-8

[32] Motzer RJ, Michaelson MD, Rosenberg J, Bukowski RM, Curti BD, George DJ, et al. Sunitinib efficacy against advanced renal cell carcinoma. J Urol. 2007 Nov;178(5): 1883-7

[33] Motzer RJ, Hutson TE, Tomczak P, Michaelson MD, Bukowski RM, Rixe O, et al. Sunitinib versus interferon alfa in metastatic renal-cell carcinoma. N Engl J Med. 2007 Jan 11;356(2):115-24

[34] Desai J, Gurney H, Pavlakis N, McArthur GA, Davis ID. Sunitinib malate in the treatment of renal cell carcinoma and gastrointestinal stromal tumor: Recommendations for patient management. Asia-Pac J Clin Oncol. 2007;3:167-76

[35] Motzer RJ, Hutson TE, Tomczak P, Michaelson MD, Bukowski RM, Oudard S, et al. Overall survival and updated results for sunitinib compared with interferon alfa in patients with metastatic renal cell carcinoma. J Clin Oncol. 2009 Aug 1;27(22):3584-90

[36] Gore ME, Szczylik C, Porta C, Bracarda S, Bjarnason GA, Oudard S, et al. Safety and efficacy of sunitinib for metastatic renal-cell carcinoma: an expanded-access trial. Lancet Oncol. 2009 Aug;10(8):757-63

[37] Escudier B, Roigas J, Gillessen S, Harmenberg U, Srinivas S, Mulder SF, et al. Phase II study of sunitinib administered in a continuous once-daily dosing regimen in patients with cytokine-refractory metastatic renal cell carcinoma. J Clin Oncol. 2009 Sep 1;27(25):4068-75

[38] Motzer R, Hutson TE, Olsen MR, Hudes G, Burke JM, Edenfield WJ, et al. Randomized phase II multicentre study of the efficacy and safety of sunitinib on the $4 / 2$ versus continuous dosing schedule as first-line therapy of metastatic renal cell carcinoma: renal EFFECT Trial. Journal of Clinical Oncology. 2011;29:(suppl 7; abstrc LBA308)

[39] Ratain MJ, Eisen T, Stadler WM, Flaherty KT, Kaye SB, Rosner GL, et al. Phase II placebo-controlled randomized discontinuation trial of sorafenib in patients with metastatic renal cell carcinoma. J Clin Oncol. 2006 Jun 1;24(16):2505-12 
[40] Escudier B, Szczylik C, Hutson TE, Demkow T, Staehler M, Rolland F, et al. Randomized phase II trial of first-line treatment with sorafenib versus interferon Alfa-2a in patients with metastatic renal cell carcinoma. J Clin Oncol. 2009 Mar 10;27(8):1280-9

[41] Escudier B, Eisen T, Stadler WM, Szczylik C, Oudard S, Siebels M, et al. Sorafenib in advanced clear-cell renal-cell carcinoma. N Engl J Med. 2007 Jan 11;356(2):125-34

[42] Escudier B, Eisen T, Stadler WM, Szczylik C, Oudard S, Staehler M, et al. Sorafenib for treatment of renal cell carcinoma: Final efficacy and safety results of the phase III treatment approaches in renal cancer global evaluation trial. J Clin Oncol. 2009 Jul $10 ; 27(20): 3312-8$

[43] Beck J, Bajetta E, Escudier B. A large open label, non comparative Phase III study of the multi-targeted kinase inhibitor sorafenib in European patients with advanced renal cell carcinoma. Presented at. 2007;ECCO(BArcelona, Spain.)

[44] Beck J, Procopio E, Verzoni S, Bajetta E, Escudier B. Large open label non-comparative clinical experience trial of the multi-targeted kinase inhibitor sorafenib in European patients with advanced RCC J Clin Oncol. 2008;26((Suppl.)):(Abstract 1621)

[45] Beck J, Procopio G, Bajetta E, Keilholz U, Negrier S, Szczylik C, et al. Final results of the European Advanced Renal Cell Carcinoma Sorafenib (EU-ARCCS) expanded-access study: a large open-label study in diverse community settings. Ann Oncol. 2011 February 15, 2011;22(8):1812-3

[46] Escudier B, Szczylik C, Porta C, Gore M. Treatment selection in metastatic renal cell carcinoma: expert consensus. Nat Rev Clin Oncol. 2012 Jun;9(6):327-37

[47] INTORSECT Trial: Phase III, randomized, open-label, multi centre study comparing temsirolimus with sorafenib as second line. . ESMO 2012: Conference proceedings, Sept 28 - Oct 2, 2012 Vienna Convention Centre, Vienna, Austria 2012

[48] Bellmunt J, Fishman M, Eisen T, Quinn D. Expert opinion on the use of first-line sorafenib in selected metastatic renal cell carcinoma patients. Expert Rev Anticancer Ther. 2011 Jun;10(6):825-35

[49] Hutson TE, Davis ID, Machiels JP, De Souza PL, Rottey S, Hong BF, et al. Efficacy and safety of pazopanib in patients with metastatic renal cell carcinoma. J Clin Oncol. 2010 Jan 20;28(3):475-80

[50] Sternberg CN, Davis ID, Mardiak J, Szczylik C, Lee E, Wagstaff J, et al. Pazopanib in locally advanced or metastatic renal cell carcinoma: results of a randomized phase III trial. J Clin Oncol. 2010 Feb 20;28(6):1061-8

[51] Rini B, Al-Marrawi MY. Pazopanib for the treatment of renal cancer. Expert Opin Pharmacother. 2011 May;12(7):1171-89 
[52] NCT00720941 Cgi. Pazopanib Versus Sunitinib in the Treatment of Locally Advanced and/or Metastatic Renal Cell Carcinoma (COMPARZ) [cited 21 July 2011]. 2011:Available from: http://clinicaltrials.gov/ct2/show/NCT00720941

[53] Rixe O, Bukowski RM, Michaelson MD, Wilding G, Hudes GR, Bolte O, et al. Axitinib treatment in patients with cytokine-refractory metastatic renal-cell cancer: a phase II study. Lancet Oncol. 2007 Nov;8(11):975-84

[54] Motzer RJ, de La Motte Rouge T, Harzstark AL, michaelson MD, Liu G, Gruenwald $\mathrm{V}$, et al. Axitinib second-line therapy for metastatic renal cell carcinoma (mRCC): Five-year (yr) overall survival (OS) data from a phase II trial. J Clin Oncol. 2011;29: (suppl; abstr 4527)

[55] Rini B, Grunwald V, Fishman MN. Axitinib for first-line metastatic renal cell carcinoma (mRCC): Overall efficacy and pharmacokinetic (PK) analyses from a randomized phase II study of Clinical Oncology. 2012;30:(suppl; abstr 4503)

[56] Rini BI, Escudier B, Tomczak P, Kaprin A, Hutson TE, Szczylik C, et al. Axitinib versus sorafenib as second-line therapy for metastatic renal cell carcinoma (mRCC): Results of phase III AXIS trial. J Clin Oncol 2011;29:(suppl; abstr 4503)

[57] Cella D, Escudier B, Rini BI, Chen HX, Bhattacharyya JC, Tarazi JC, et al. Patient-reported outcomes (PROs) in a phase III AXIS trial of axitinib versus sorafenib as second-line therapy for metastatic renal cell carcinoma (mRCC) J Clin Oncol. 2011;29 (suppl) abstr 4504

[58] Gommersall L, Hayne D, Lynch C, Joseph JV, Arya M, Patel HR. Allogeneic stem-cell transplantation for renal-cell cancer. Lancet Oncol. 2004 Sep;5(9):561-7

[59] Yang JC, Haworth L, Sherry RM, Hwu P, Schwartzentruber DJ, Topalian SL, et al. A randomized trial of bevacizumab, an anti-vascular endothelial growth factor antibody, for metastatic renal cancer. N Engl J Med. 2003 Jul 31;349(5):427-34

[60] Presta LG, Chen H, O'Connor SJ, Chisholm V, Meng YG, Krummen L, et al. Humanization of an anti-vascular endothelial growth factor monoclonal antibody for the therapy of solid tumors and other disorders. Cancer Res. 1997 Oct 15;57(20):4593-9

[61] Escudier B, Bellmunt J, Negrier S, Bajetta E, Melichar B, Bracarda S, et al. Phase III trial of bevacizumab plus interferon alfa-2a in patients with metastatic renal cell carcinoma (AVOREN): final analysis of overall survival. J Clin Oncol. 2007 May 1;28(13): 2144-50

[62] Rini BI, Halabi S, Rosenberg JE, Stadler WM, Vaena DA, Archer L, et al. Phase III trial of bevacizumab plus interferon alfa versus interferon alfa monotherapy in patients with metastatic renal cell carcinoma: final results of CALGB 90206. J Clin Oncol. 2010 May 1;28(13):2137-43 
[63] McDermott DF, George DJ. Bevacizumab as a treatment option in advanced renal cell carcinoma: an analysis and interpretation of clinical trial data. Cancer Treat Rev. 2010 May;36(3):216-23

[64] Beuvink I, Boulay A, Fumagalli S, Zilbermann F, Ruetz S, O'Reilly T, et al. The mTOR inhibitor RAD001 sensitizes tumor cells to DNA-damaged induced apoptosis through inhibition of p21 translation. Cell. 2005 Mar 25;120(6):747-59

[65] Hudes G, Carducci M, Tomczak P, Dutcher J, Figlin R, Kapoor A, et al. Temsirolimus, interferon alfa, or both for advanced renal-cell carcinoma. N Engl J Med. 2007 May 31;356(22):2271-81

[66] Hidalgo M, Buckner JC, Erlichman C, Pollack MS, Boni JP, Dukart G, et al. A phase I and pharmacokinetic study of temsirolimus (CCI-779) administered intravenously daily for 5 days every 2 weeks to patients with advanced cancer. Clin Cancer Res. 2006 Oct 1;12(19):5755-63

[67] Motzer RJ, Escudier B, Oudard S, Hutson TE, Porta C, Bracarda S, et al. Efficacy of everolimus in advanced renal cell carcinoma: a double-blind, randomised, placebocontrolled phase III trial. Lancet. 2008 Aug 9;372(9637):449-56

[68] Fisher R, Pickering L, Larkin J. New targeted therapies for renal cell carcinoma. Expert Opin Investig Drugs. 2011 Jul;20(7):933-45

[69] Eisen T, Joensuu H, Nathan PD, Harper PG, Wojtukiewicz MZ, Nicholson S, et al. Regorafenib for patients with previously untreated metastatic or unresectable renalcell carcinoma: a single-group phase 2 trial. Lancet Oncol. 2012 Oct;13(10):1055-62

[70] Nosov D, Bhargava P, Esteves WB, Strahs AL, Lipatov ON, Lyulkp OO, et al. Final analysis of the phase II randomized discontinuation trial (RDT) of tivozanib (AV-951) versus placebo in patients with renal cell carcinoma (RCC). J Clin Oncol 2011;29: (suppl; abstr 4503)

[71] Kabbinavar FF, Srinivas S, Hauke RJ, Amato RJ, Esteves WB, Cotreau MM, et al. Results from a phase I trial of tivozanib (AV-951) combined with temsirolimus therapy in patients (pts) with renal cell carcinoma (RCC). J Clin Oncol 2011;29((suppl)):abstr 4549

[72] Motzer R, Nosov D, Eisen T, Bondarenko I, Lesovoy V, Lipatov ON, et al. Tivozanib versus sorafenib as initial targeted therapy for patients with advanced renal cell carcinoma: Results from a phase III randomized, open-label, multicenter trial. J Clin Oncol 30, 2012).

[73] Angevin E, Grünwald V, Castellano DE, Lin CC, Gschwend JE, Harzstark AL, et al. A phase II study of dovitinib (TKI258), an FGFR- and VEGFR-inhibitor, in patients with advanced or metastatic renal cell cancer (mRCC). J Clin Oncol 2011;29((suppl)): (abstr 4551) 
[74] Hutson TE. Targeted therapies for the treatment of metastatic renal cell carcinoma: clinical evidence. Oncologist. 2011;16 Suppl 2:14-22

[75] Feldman DR, Baum MS, Ginsberg MS, Hassoun H, Flombaum CD, Velasco S, et al. Phase I trial of bevacizumab plus escalated doses of sunitinib in patients with metastatic renal cell carcinoma. J Clin Oncol. 2009 Mar 20;27(9):1432-9

[76] Gollob JA, Rathmell WK, Richmond TM, Marino CB, Miller EK, Grigson G, et al. Phase II trial of sorafenib plus interferon alfa- $2 b$ as first- or second-line therapy in patients with metastatic renal cell cancer. J Clin Oncol. 2007 Aug 1;25(22):3288-95

[77] Ryan CW, Goldman BH, Lara PN, Jr., Mack PC, Beer TM, Tangen CM, et al. Sorafenib with interferon alfa- $2 b$ as first-line treatment of advanced renal carcinoma: $a$ phase II study of the Southwest Oncology Group. J Clin Oncol. 2007 Aug 1;25(22): 3296-301

[78] Jonasch E, Corn P, Pagliaro LC, Warneke CL, Johnson MM, Tamboli P, et al. Upfront, randomized, phase 2 trial of sorafenib versus sorafenib and low-dose interferon alfa in patients with advanced renal cell carcinoma: clinical and biomarker analysis. Cancer. 2010 Jan 1;116(1):57-65

[79] Escudier B, Pluzanska A, Koralewski P, Ravaud A, Bracarda S, Szczylik C, et al. Bevacizumab plus interferon alfa-2a for treatment of metastatic renal cell carcinoma: a randomised, double-blind phase III trial. Lancet. 2007 Dec 22;370(9605):2103-11

[80] Rini BI, Halabi S, Rosenberg JE, Stadler WM, Vaena DA, Ou SS, et al. Bevacizumab plus interferon alfa compared with interferon alfa monotherapy in patients with metastatic renal cell carcinoma: CALGB 90206. J Clin Oncol. 2008 Nov 20;26(33): $5422-8$

[81] Negrier S, Gravis G, Perol D, Chevreau C, Delva R, Bay JO, et al. Temsirolimus and bevacizumab, or sunitinib, or interferon alfa and bevacizumab for patients with advanced renal cell carcinoma (TORAVA): a randomised phase 2 trial. Lancet Oncol. 2011 Jul;12(7):673-80

[82] INTORACT trial: global phase IIIb, randomized, open-label, multi-centre study, comparing temsirolimus plus bevacizumab with interferon pluas bevacizumab as first line treatment in clear cell metastatic renal cell carcinoma. ESMO 2012: Conference proceedings, Sept 28 - Oct 2, 2012. Vienna Convention Centre, Vienna, Austria. 2012

[83] Sosman JA, Flaherty KT, Atkins MB, McDermott DF, Rothenberg WL, Vermeulen $\mathrm{WL}$, et al. Updated results of phase I trial of sorafenib (S) and bevacizumab (B) in patients with metastatic renal cell cancer (mRCC). J Clin Oncol. 2008;26 (May 20 Suppl):Abstr 5011

[84] Azad NS, Posadas EM, Kwitkowski VE, Steinberg SM, Jain L, Annunziata CM, et al. Combination targeted therapy with sorafenib and bevacizumab results in enhanced toxicity and antitumor activity. J Clin Oncol. 2008 Aug 1;26(22):3709-14 
[85] NCT00378703 Cgi. Bevacizumab, Sorafenib, and Temsirolimus in Treating Patients With Metastatic Kidney Cancer (BeST) [cited 16 Dec 2010]. 2006:Available from http:// clinicaltrials.gov/ct2/show/NCT00378703

[86] Bellmunt J. Future developments in renal cell carcinoma. Ann Oncol. 2009 May;20 Suppl 1:i13-7

[87] Motzer RJ, Michaelson MD, Redman BG, Hudes GR, Wilding G, Figlin RA, et al. Activity of SU11248, a multitargeted inhibitor of vascular endothelial growth factor receptor and platelet-derived growth factor receptor, in patients with metastatic renal cell carcinoma. J Clin Oncol. 2006 Jan 1;24(1):16-24

[88] Dutcher JP, Wilding G, Hudes GR, Stadler WM, Kim S, Tarazi JC, et al. Sequential axitinib (AG-013736) therapy of patients (pts) with metastatic clear cell renal cell cancer (RCC) refractory to sunitinib and sorafenib, cytokines and sorafenib, or sorafenib alone. J Clin Oncol. 2008;26(May 20 suppl):abstr 5127

[89] NCT1217931 Cgi. Sequential Two-agent Assessment in Renal Cell Carcinoma Therapy [cited 17 May 2011]. 2011:Available from: http://clinicaltrials.gov/ct2/show/ NCT01217931?term=NCT\&rank=1

[90] Dudek AZ, Zolnierek J, Dham A, Lindgren BR, Szczylik C. Sequential therapy with sorafenib and sunitinib in renal cell carcinoma. Cancer. 2009 Jan 1;115(1):61-7

[91] NCT00732914 Cgi. Sequential Study to Treat Renal Cell Carcinoma [cited 18 Oct 2010]. 2010:Available from: http://clinicaltrials.gov/ct2/show/NCT00732914? term=NCT\&rank=1

[92] Motzer RJ, Bacik J, Mariani T, Russo P, Mazumdar M, Reuter V. Treatment Outcome and Survival Associated With Metastatic Renal Cell Carcinoma of Non-Clear-Cell Histology. J Clin Oncol. 2002 May 1, 2002;20(9):2376-81

[93] Tazi el M, Essadi I, Tazi MF, Ahellal Y, M'Rabti H, Errihani H. Advanced treatments in non-clear renal cell carcinoma. Urol J. 2011 Winter;8(1):1-11

[94] Schmidt LS, Warren MB, Nickerson ML, Weirich G, Matrosova V, Toro JR, et al. BirtHogg-Dube syndrome, a genodermatosis associated with spontaneous pneumothorax and kidney neoplasia, maps to chromosome 17p11.2. Am J Hum Genet. 2001 Oct; 69(4):876-82

[95] Gordon MS, Hussey M, Nagle RB, Lara PN, Jr., Mack PC, Dutcher J, et al. Phase II study of erlotinib in patients with locally advanced or metastatic papillary histology renal cell cancer: SWOG S0317. J Clin Oncol. 2009 Dec 1;27(34):5788-93

[96] di Lorenzo G, Porta C, Bellmunt J, Sternberg C, Kirkali Z, Staehler M, et al. Toxicities of targeted therapy and their management in kidney cancer. Eur Urol. 2011 Apr; 59(4):526-40 
[97] Ravaud A. Treatment-Associated Adverse Event Management in the Advanced Renal Cell Carcinoma Patient Treated with Targeted Therapies. Oncologist. 2011;16(suppl 2):32-44

[98] Izzedine H, Ederhy S, Goldwasser F, Soria JC, Milano G, Cohen A, et al. Management of hypertension in angiogenesis inhibitor-treated patients. Ann Oncol. 2009 May;20(5):807-15

[99] Rixe O, Billemont B, Izzedine H. Hypertension as a predictive factor of Sunitinib activity. Ann Oncol. 2007 Jun;18(6):1117

[100] Sternberg CN. Randomised, double-blind phase III study of pazopanib in patients with advaced/metastatic renal cell carcinoma (MRCC), ESMO: Pazopanib in advanced MRCC - late breaker published 11/10/2011 by cancer reported Jo Armstrong. 2010

[101] Khakoo AY, Kassiotis CM, Tannir N, Plana JC, Halushka M, Bickford C, et al. Heart failure associated with sunitinib malate: a multitargeted receptor tyrosine kinase inhibitor. Cancer. 2008 Jun;112(11):2500-8

[102] Bhojani N, Jeldres C, Patard JJ, Perrotte P, Suardi N, Hutterer G, et al. Toxicities associated with the administration of sorafenib, sunitinib, and temsirolimus and their management in patients with metastatic renal cell carcinoma. Eur Urol. 2008 May; 53(5):917-30

[103] Grunwald V, Heinzer H, Fiedler W. Managing side effects of angiogenesis inhibitors in renal cell carcinoma. Onkologie. 2007 Oct;30(10):519-24

[104] Keefe D, Bowen J, Gibson R, Tan T, Okera M, Stringer A. Noncardiac vascular toxicities of vascular endothelial growth factor inhibitors in advanced cancer: a review. Oncologist. 2011;16(4):432-44

[105] Rini BI, Cohen DP, Lu DR, Chen I, Hariharan S, Gore ME, et al. Hypertension as a biomarker of efficacy in patients with metastatic renal cell carcinoma treated with sunitinib. J Natl Cancer Inst. 2011 May 4;103(9):763-73

[106] Scartozzi M, Galizia E, Chiorrini S, Giampieri R, Berardi R, Pierantoni C, et al. Arterial hypertension correlates with clinical outcome in colorectal cancer patients treated with first-line bevacizumab. Ann Oncol. 2009 Feb;20(2):227-30

[107] Adams VR, Leggas M. Sunitinib malate for the treatment of metastatic renal cell carcinoma and gastrointestinal stromal tumors. Clin Ther. 2007 Jul;29(7):1338-53

[108] Ravaud A. How to optimise treatment compliance in metastatic renal cell carcinoma with targeted agents. Ann Oncol. 2009 May;20 (Suppl 1):i7-12

[109] Davis MP, Figlin R, Hutson TE. Asthenia and fatigue as potential biomarkers of sunitinib efficacy in metasatic renal cell carcinoma. Eur J Cancer. 2011;47:(Suppl 1):s135 (Abstract 1139) 
[110] Poprach A, Pavlik T, Melichar B, Puzanov I, Dusek L, Bortlicek Z, et al. Skin toxicity and efficacy of sunitinib and sorafenib in metastatic renal cell carcinoma: a national registry-based study. Ann Oncol. 2012 Jun 13

[111] Schmidinger M, Vogl UM, Bojic M, Lamm W, Heinzl H, Haitel A, et al. Hypothyroidism in patients with renal cell carcinoma: blessing or curse? Cancer. Feb 1;117(3): $534-44$

[112] Donskov F, Carus A, Barrios C. Neutropenia and thrombocytopenia during treatment as biomarkers of sunitinib efficacy in patients with metastatic renal cell carcinoma (mRCC). Eur J Cancer. 2011;47:(Suppl 1):S136 (Abstract 1141)

[113] Dadydeen DA, Jagannthan JP, Ramaiya NH. Pneumonitis associated with mTOR therapy in patients with metastatic renal cell carcinoma: Incidence, radiographic findings, and correlation with clnical outcome. 2011 ASCO Annual Meeting Proceedings (Post Meeting Edition). J Clin Oncol. 2011;29:(15 Suppl): Abstract e15176

[114] Lee CK, Marschner IC, Simes RJ, Voysey M, Egleston B, Hudes G, et al. Increase in cholesterol predicts survival advantage in renal cell carcinoma patients treated with temsirolimus. Clin Cancer Res. 2012 Jun 1;18(11):3188-96

[115] Armstrong A, George D, Halabi S. Serum lactate dehydrogenase (LDH) as a biomarker for survival with mTOR inhibition in patients with metastatic renal cell carcinoma (RCC). 2010 ASCO Annual Meeting Proceedings (Post-Meeting Edition). J Clin Oncol. 2010;28:(15 Suppl): Abstract 4631

[116] Bukowski R, Cella D, Gondek K, Escudier B. Effects of sorafenib on symptoms and quality of life: results from a large randomized placebo-controlled study in renal cancer. Am J Clin Oncol. 2007 Jun;30(3):220-7

[117] Escudier B, Porta C, Bono P, De Giorgi U, Parikh O, Hawkins RE, et al. Patient preference between pazopanib (Paz) and sunitinib (Sun): Results of a randomized double-blind, placebo-controlled, cross-over study in patients with metastatic renal cell carcinoma (mRCC) - PISCES study, NCT 01064310. Journal of Clinical Oncology. 2012;30(18s):CRA4502

[118] Escudier B, Porta C, Bono P, De Giorgi U, Parikh O, Hawkins RE, et al. Patient preference between pazopanib (Paz) and sunitinib (Sun): Results of a randomized double-blind, placebo-controlled, cross-over study in patients with metastatic renal cell carcinoma (mRCC)-PISCES study, NCT 01064310. conference proceedings. 2012;Sept 26 - Oct 2, 2012. Vienna Convention Centre, Vienna, Austria 
